\title{
Adaptation and Psychometric Study of the Coronavirus Anxiety Scale (CAS) to the Mexican Population
}

\author{
Ferran Padrós-Blázquez ${ }^{*}$, Gersaín Trujillo-Alonso², Paulino Salinas-García², \\ Yunuén Reséndiz-Ramírez² ${ }^{2}$ Conne Lizbeth González-García², Rocío Montoya-Pérez ${ }^{3}$, \\ María Patricia Martínez-Medina² \\ ${ }^{1}$ Facultad de Psicología, Universidad Michoacana de San Nicolás de Hidalgo, Michoacán, México \\ ${ }^{2}$ Hospital General de Morelia, Morelia, México \\ ${ }^{3}$ Instituto de Investigaciones Químico-Biológicas, Universidad Michoacana de San Nicolás de Hidalgo, Michoacán, México \\ Email: ^fpadros@umich.mx, ${ }^{\star}$ fpadros@uoc.edu
}

How to cite this paper: Padrós-Blázquez, F., Trujillo-Alonso, G., Salinas-García, P., Reséndiz-Ramírez, Y., González-García, C. L., Montoya-Pérez, R., \& Martínez-Medina, M. P. (2021). Adaptation and Psychometric Study of the Coronavirus Anxiety Scale (CAS) to the Mexican Population. Psychology, 12, 17901798.

https://doi.org/10.4236/psych.2021.1211108

Received: October 22, 2021

Accepted: November 22, 2021

Published: November 25, 2021

Copyright $\odot 2021$ by author(s) and Scientific Research Publishing Inc. This work is licensed under the Creative Commons Attribution International License (CC BY 4.0).

http://creativecommons.org/licenses/by/4.0/

\begin{abstract}
Due to the increased anxiety levels due to COVID-19, brief screening instruments are required to detect it. Recently, Lee has developed an instrument with these characteristics, the Coronavirus Anxiety scale (CAS), showing adequate psychometric properties. Therefore, this work aimed to adapt and study the main psychometric characteristics of CAS in the Mexican population. The CAS Scale was administered simultaneously as the BAI, Goldberg Anxiety and Depression Brief Screening Scales, and the MBI to 262 people exposed to COVID-19 (medical staff, nurses, and patients). A unifactorial structure and high reliability ( $\alpha=.848$ ) were corroborated; the relationship with the other scales was consistent with the theory. It can be concluded that the CAS is adequate to evaluate the presence of anxiety symptoms due to COVID-19 in the population of Michoacan (Mexico).
\end{abstract}

\section{Keywords}

Coronavirus, Anxiety, Reliability, Confirmatory Factor Analysis, Scale

\section{Introduction}

In a globalized world, it would be thought that the availability of information is an advantage, however, in the case of the recent pandemic, excess information has caused globally high levels of anxiety and depression, reaching misinformation extremes with the conspiracy theories (Larsen, Donaldson, Liew, \& Mohanty, 2021). On the other hand, after the WHO (2020) released COVID-19 in De- 
cember 2019, the disease has spread throughout the planet, causing many fatalities Baloch et al. (2020). Health care personnel are essential workers at risk for exposure to patients or infectious materials (Gómez-Ochoa et al., 2021). Lifestyle modifications, partly imposed by the authorities and partly due to personal and individual precautions, have been remarkable. The immediate consequences of such circumstances is an increase in concern, which is adaptive and desirable if it leads to behaviors that reduce the risk of suffering the consequences or mitigate the effects of the threat (Padrós-Blázquez, López-Solà, Cruz-García, \& Martínez-Medina, 2019). In this case, it can lead to using a mask, gloves, hand washing, preserving a healthy distance, etc. Nevertheless, sometimes it can become pathological, and cause an increase in worries about thoughts, sleep problems, among other alterations, as has already been reported concerning COVID-19 (Roy et al., 2020).

At an international level, a higher risk of stress, anxiety and depression disorders has recently been reported in healthcare personnel due to the pandemic (Elbay, Kurtulmuş, Arpacioğlu, \& Karadere, 2020; Huang \& Zhao, 2020; Liu et al., 2020; Luceño-Moreno et al., 2020; Preti et al., 2020). Also, in Mexico, an increase of up to $51 \%$ in the prevalence of anxiety has been observed (Priego-Parra et al., 2020). Also, It has been reported by the Mexican Institute of Youth that during the pandemic, three out of every five young people (18 to 25 years old) showed symptoms of depression and 57 percent, anxiety (Gobierno de México). That is why it is necessary to have short and easy-to-apply instruments to detect anxiety risk, especially in high-risk populations such as healthcare personnel or patients.

Recently, Lee (2020) has constructed the Coronavirus Anxiety Scale (CAS); it is a very brief instrument, with only 5 items, to assess the risk of pathological anxiety related to COVID-19, which has shown excellent psychometric properties as high reliability, with a Cronbach's alpha value of .93. The five items were adequate, which form a unifactorial structure with an excellent fit observed from a Confirmatory Factor Analysis (CFA). Likewise, the original work by Lee (2020) offers some evidence of concurrent validity. On the other hand, no differences were observed by sex and a low and negative relationship with age.

Because in Mexico, there is no instrument to detect anxiety levels derived from COVID-19 by way of screening, the objective is to adapt and study the internal structure, goodness of the items, reliability and evidence of the validity of the CAS scale. Likewise, the relationship of the CAS scores with sex, age and type of sample (medical staff, nursing staff and patients) is analyzed.

\section{Method}

\subsection{Participants}

A sample of 262 adults with high exposure to COVID-19 was used, which were medical personnel $(n=76)$, nurses $(n=136)$ and general hospital patients $(n=$ 50). Regarding the sociodemographic characteristics of the samples, the age ranged 
between 18 and 81 years $(\mathrm{M}=38.66$; $\mathrm{SD}=12.06)$ and the majority of participants were women $(\mathrm{n}=165 ; 63.0 \%)$. Regarding schooling, the variable was distributed as follows; 15 (5.7\%) reported having primary studies, $13(5.0 \%)$ secondary, $42(16.0 \%)$ preparatory, $85(32.4 \%)$ undergraduate, $72(27.5 \%)$ specialized, 28 (10.7\%) master's, $2(.8 \%) \mathrm{PhD}$ and 5 (1.9\%) did not respond. The sampling was incidental and for convenience.

\subsection{Measures}

The Coronavirus Anxiety Scale (CAS) object of study of this work has been described above (Lee, 2020). In a preliminary stage, the cultural adaptation of the language of the instrument was carried out. The scale was translated and later evaluated and approved regarding the items' accuracy, syntax, and semantics by 3 judges (two doctors and a psychologist).

The BAI (Beck Anxiety Inventory) assesses the presence of anxiety symptoms, the adaptation in Spanish to the Mexican population carried out by Robles, Varela, Jurado, \& Páez (2001). It has 21 items with 4 response options (None, Slightly, Moderately and severely). The Mexican version showed adequate reliability ( $\alpha=.83$ and .91) (Robles et al., 2001; Padrós-Blázquez, Montoya-Pérez, Bravo-Calderón, \& Martínez-Medina, 2020).

Maslach's Burnout Inventory (MBI) has been adapted to the Mexican population (Aranda-Beltrán, Pando-Moreno, \& Salazar Estrada, 2016). It is composed of 22 items, contains three factors; emotional exhaustion with an alpha value of .835 , depersonalization of $(\alpha=.407)$ and Lack of Realization $(\alpha=.733)$. The alpha value of the total scale was somewhat low $(\alpha=.658)$.

Brief Anxiety and Depression Screening Scale by Goldberg, Prisciandaro, \& Williams (2012), as its name indicates, consists of two subscales, one for anxiety and the other for depression. Each subscale has 5 dichotomous response items. It has shown good psychometric characteristics in the Mexican population (Goldberg et al., 2017). In the present investigation, the reactants with an affirmative answer were added directly.

\subsection{Procedure}

The research protocol was reviewed and approved by the General Hospital of Morelia ethics committee. The CAS was translated and retranslated by two bilingual people. Subsequently, three medical specialty students invited the participants (medical staff, nursing staff and patients) to respond to the questionnaires through a link on the Internet. All signed informed consent and their participation were voluntary and anonymous. Information was requested on their age, sex, marital status and education, in addition to responding to the CAS, BAI, Maslach's Burnout inventory and Goldberg's Brief Anxiety and Depression Screening Scale (approximate duration of responding to the entire battery was 15 minutes).

\subsection{Data Analysis}

A Confirmatory Factor Analysis (CFA) using WLSMV (Weighted Least Square) 
estimation with a reparameterization with a value of $\delta=.05$ and forcing a nonorthogonal factor structure was applied to one factor model. Acceptable model fit is defined according to the following criteria: Index of Normed Fit (NFI) > .90; Non-Normed Fit Index $(\mathrm{NNFI})>.90$; Comparative Fit Index $(\mathrm{CFI})>.90, \chi^{2}$; $p>.01$ and values $\chi^{2} / \mathrm{df}>5$, but a good fit of the model is attained when NFI > .95; NNFI > .95; CFI > .95, $\chi^{2} ; p>.05$ and values $\chi^{2} / \mathrm{df}>3$, (Bentler, 1990; Hu \& Bentler, 1999).

Later, to corroborate the goodness of the items, an item analysis was performed, using the Pearson correlation of each item with the total score of the corrected scale (without counting the item itself), and after calculating the Cronbach's alpha if the item was eliminated. Minimum correlation (.30) was established as a criterion of the item of goodness and no increase of the alpha value was observed if the item was eliminated (Costello \& Osborne, 2005). Subsequently, the study of the internal reliability was carried out using Cronbach's alpha, where values equal to or above .70 are acceptable (Campo-Arias \& Oviedo, 2008).

The evidence of the validity of the CAS was assessed through Pearson correlations with the other variables. Pearson's correlations and Student Fisher's t were used to infer relationships or differences between variables. In the case of significant findings, we computed Cohen's $d$ to estimate the effect size of the difference.

Finally, the analyzes were carried out with the 22.0 program (IBM Corp Released, 2013), except for the CFA, which used the MPlus Versión 7.0 program (Muthén \& Muthén, 2011).

\section{Results}

The CFA corroborated the unfactorial internal structure of the Lee Scale. The results show that the Satorra-Bentler $\chi^{2}(\mathrm{df}=5)$ value of 10.77 was not significant $(p=.0561)$, the $\chi^{2} / \mathrm{df}$ index was 2.15 , indicating an excellent fit. On the other hand, all the other indices; NFI $=.948 ;$ NNFI $=.942$; CFI $=.971$ and RMSEA value $=.066$ (values $<.08$ indicate adequate fit) is also interpreted as a good fit (see one-factor model in Figure 1).

The internal consistency of the scale was high $(\alpha=.848)$. Regarding the goodness of items: the means obtained values above the value 1 and up to 1.75. The indices of the standard deviations were close to the value of the unit. All items showed a moderate to high correlation with the corrected total scale score (excluding the item itself), and no item when eliminated increases the Cronbach's alpha value of the full scale (see Table 1 ).

Regarding the evidence of concurrent validity, a very high and positive correlation was observed with the BAI scale, which also measures anxiety, but generically. On the other hand, the correlations were moderate and positive with the anxiety and depression scales of the Goldberg brief screening scale. Correlations were also moderate and positive with the full Burnout scale (MBI) and emotional exhaustion subscale. Finally, the two subscales of depersonalization and personal fulfillment of the MBI were low and positive (see Table 2). 


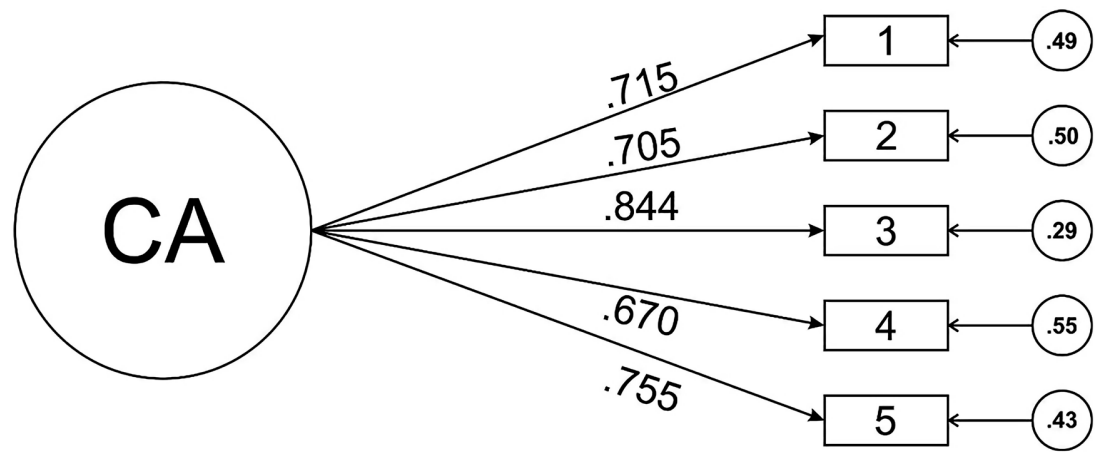

Figure 1. One-factor model of the CAS scale.

Table 1. Mean, standard deviation, corrected correlation (without the item itself) and Cronbach's alpha if the item is eliminated for each item of the Lee Scale.

\begin{tabular}{ccccc}
\hline Item & Mean & Standard deviation & $\begin{array}{c}\text { Correlation with } \\
\text { full scale (corrected) }\end{array}$ & $\begin{array}{c}\text { Alpha of the full scale if } \\
\text { the item is removed }\end{array}$ \\
\hline 1 & 1.23 & .81 & .647 & .820 \\
2 & 1.75 & 1.15 & .636 & .836 \\
3 & 1.23 & .88 & .760 & .789 \\
4 & 1.16 & .80 & .621 & .827 \\
5 & 1.11 & .81 & .680 & .813 \\
\hline
\end{tabular}

Table 2. Correlations between the Lee scale and the other administered instruments and subscales.

\begin{tabular}{cccccccc}
\hline Scale & BAI & Ans-G & Dep-G & Emo-E & Desp & L-Rea & MBI \\
\hline LEE & .758 & .501 & .489 & .513 & .365 & .322 & .508 \\
\hline
\end{tabular}

BAI = Beck Anxiety Inventory; Ans-G = Anxiety Goldberg Brief Screening Scale; Dep-G $=$ Depression Goldberg Brief Screening Scale; Emo-E = Emotional Exhaustion Scale; Desp $=$ Depersonalization Scale; L-Rea = Lack of Realization Scale; MBI = Maslach's Burnout Inventory (MBI). ${ }^{\star}$ All correlations were significant $(p<.001)$.

The mean CAS score was $6.47(\mathrm{SD}=3.56)$ and the Mode was 5. The total scale scores ranged from 0 to 19 . The mean $(M=7.35$; $S D=3.60)$ of the CAS of the participants from Female sex was superior $\left(\mathrm{t}_{(260)}=-5.547 ; p<.001 ; \mathrm{d}=.726\right)$ compared to that shown by male participants $(\mathrm{M}=4.96$; $\mathrm{SD}=2.95)$. On the other hand, a low and negative relationship was observed between the CAS score and age $(\mathrm{r}=-.182 ; p=.003)$. On the other hand, differences were observed $\left(\mathrm{F}_{(2)}\right.$ $=46.286 ; p<.001)$ when the means in the three subsamples were compared. The nursing staff showed a significantly higher score $(\mathrm{M}=7.82$; $\mathrm{SD}=3.35)$ than that shown by the two groups, and the mean of the medical staff $(\mathrm{M}=6.37 ; \mathrm{SD}=$ $2.15)$, was higher than that shown by the patients $(\mathrm{M}=2.94 ; \mathrm{SD}=3.43)$.

\section{Discussion}

The main objective of the present work was to adapt and study the internal struc- 
ture, corroborate the goodness of the items, the internal consistency, and provide evidence of the validity of the CAS.

To the internal structure, the unifactorial model showed an adequate fit, coinciding with the original study by Lee (2020). Regarding the goodness of the items, it can be concluded that all were adequate. The 5 items correlated with the scale's total without the item itself above .6, and none, when eliminated, increases the value of Cronbach's alpha of the total scale. Regarding internal consistency, although somewhat lower than that shown in the original version (Lee, 2020), the reliability index was adequate, especially considering it only contains five items.

The correlations found between the CAS and the other scales were congruent and expected. The highest (and positive) correlation was with the BAI (Robles et al., 2001) that measures anxiety in a generic way and with a broad representation, the symptoms of most anxiety disorders (Sanz \& Navarro, 2003), which It was to be expected because the CAS also measures anxiety. The correlation with the anxiety subscale of the Brief Anxiety and Depression Screening Scale of Goldberg et al. (2012) was moderate and positive, somewhat higher than that shown with the depression subscale, which is also expected due to the high correlation between anxiety and depressive symptoms (Bardhoshi, Duncan, \& Erford, 2016). Finally, the relationships between the CAS with the MBI subscales (Aranda-Beltrán et al., 2016) and the total score were moderate or low positive, coinciding with the moderate relationships between anxiety measurements and the MBI subscales reported in other studies (Creedy et al., 2017; Golonka et al., 2019).

The highest scores found in women do not coincide with what was reported in the study by Lee (2020), but they are congruent with the usual reports of a higher prevalence of anxiety disorders in females compared to males (Bandelow \& Michaelis, 2015). Although significant, the effect size is minimal, the low and negative relationship between the CAS score and age. This coincides with what was found in the original study (Lee, 2020) and with what was reported in studies carried out with the BAI in Mexico (Padrós-Blázquez et al., 2020).

The higher score shown by health personnel for patients could be that patients may be anxious or more concerned about the disease they suffer than about the possible contagion. It can also be explained by an absence of perceived threat, even denial of COVID-19, due to explanations such as conspiracy theories, etc., shared by the general population (Swami \& Barron, 2020). On the other hand, the higher level of anxiety shown by the nursing staff regarding the doctor coincides with the data from other studies (Li et al., 2016), although the latter is related to work pressure.

\section{Limitations}

The present study has limitations that should be mentioned. The sampling used was incidental and for convenience, it would be desirable in future studies to 
perform a random sampling. Likewise, samples from other states of the Republic should be used to increase the representativeness of the results. In future research carried out with the Mexican population, the test-retest reliability of the scale should be studied. It would also be interesting to carry out studies on the sensitivity to change of the scale in patients with high anxiety levels due to the coronavirus after a successful treatment.

\section{Conclusion}

As the main conclusion, the CAS is a valid and reliable instrument to be used as a very brief, easy-to-apply and screening instrument to detect anxiety risk, especially in high-risk populations such as healthcare personnel or patients in the Michoacán population.

\section{Ethics Statement}

Approval of the ethics committee of the Hospital General de Morelia, March 2020.

\section{Conflicts of Interest}

The authors declared no potential conflicts of interest for this article's research, authorship, and/or publication.

\section{References}

Aranda-Beltrán, C., Pando-Moreno, M., \& Salazar-Estrada, J. G. (2016). Confiabilidad y validación de la escala Maslach Burnout Inventory (HSS) en trabajadores del occidente de México [Reliability and Validation of the Scale Maslach Burnout Inventory (HSS) in Workers in Western México]. Revista Salud Uninorte, 32, 218-227. https://doi.org/10.14482/sun.32.2.8828

Baloch, S., Baloch, M. A., Zheng, T., \& Pei, X. (2020). The Coronavirus Disease 2019 (COVID-19) Pandemic. The Tohoku Journal of Experimental Medicine, 250, 271-278. https://doi.org/10.1620/tjem.250.271

Bandelow, B., \& Michaelis, S. (2015). Epidemiology of Anxiety Disorders in the 21st Century. Dialogues in Clinical Neuroscience, 17, 327-335. https://doi.org/10.31887/DCNS.2015.17.3/bbandelow

Bardhoshi, G., Duncan, K., \& Erford, B. (2016). Psychometric Meta-Analysis of the English Version of the Beck Anxiety Inventory. Journal of Counseling \& Development, 94, 356-373. https://doi.org/10.1002/jcad.12090

Bentler, P. M. (1990). Comparative Fit Indexes in Structural Models. Psychological Bulletin, 107, 238-246. https://doi.org/10.1037/0033-2909.107.2.238

Campo-Arias, A., \& Oviedo, H. C. (2008). Propiedades Psicométricas de una Escala: La Consistencia Interna [Psychometric Properties of a Scale: Internal Consistency]. Revista de Salud Pública, 10, 831-839.

Costello, A. B., \& Osborne, J. W. (2005). Best Practices in Exploratory Factor Analysis. Practical Assessment Research \& Evaluation, 10, 1-9.

Creedy, D. K., Sidebotham, M., Gamble, J., Pallant, J., \& Fenwick, J. (2017). Prevalence of Burnout, Depression, Anxiety and Stress in Australian Midwives: A Cross-Sectional Sur- 
vey. BMC Pregnancy and Childbirth, 17, Article No. 13.

https://doi.org/10.1186/s12884-016-1212-5

Elbay, R. Y., Kurtulmuş, A., Arpacioğlu, S., \& Karadere, E. (2020). Depression, Anxiety, Stress Levels of Physicians and Associated Factors in Covid-19 Pandemics. Psychiatry Research, 290, Article ID: 113130. https://doi.org/10.1016/j.psychres.2020.113130

Gobierno de México, Secretaría de Salud (2021). https://www.gob.mx/salud/prensa/pandemia-impacta-en-distintos-ambitos-a-adolesce ntes-y-jovenes-voces-19?idiom $=\mathrm{es}$

Goldberg, D. P., Prisciandaro, J. J., \& Williams, P. (2012). The Primary Health Care Version of ICD-11: The Detection of Common Mental Disorders in General Medical Settings. General Hospital Psychiatry, 34, 665-670.

https://doi.org/10.1016/j.genhosppsych.2012.06.006

Goldberg, D., Reed, G. M., Robles, R., Minhas, F., Razzaque, B., Fortes, S., de Jesus Mari, J., Pong Lam, T., Ángel Garcia, J., Gask, L., Dowell, A. C., Rosendal, M., Mbatia, J. K., \& Saxena, S. (2017). Screening for Anxiety, Depression, and Anxious Depression in Primary Care: A Field Study for ICD-11 PHC. Journal of Affective Disorders, 213, 199-206. https://doi.org/10.1016/j.jad.2017.02.025

Golonka, K., Mojsa-Kaja, J., Blukacz, M., Gawłowska, M., \& Marek, T. (2019). Occupational Burnout and Its Overlapping Effect with Depression and Anxiety. International Journal of Occupational Medicine and Environmental Health, 32, 229-244. https://doi.org/10.13075/ijomeh.1896.01323

Gómez-Ochoa, S. A., Franco, O. H., Rojas, L. Z., Raguindin, P. F., Roa-Díaz, Z. M., Wyssmann, B. M. et al. (2021). COVID-19 in Health-Care Workers: A Living Systematic Review and Meta-Analysis of Prevalence, Risk Factors, Clinical Characteristics, and Outcomes. American Journal of Epidemiology, 190, 161-175.

https://doi.org/10.1093/aje/kwaa191

Hu, L., \& Bentler, P. M. (1999). Cutoff Criteria for Fit Indexes in Covariance Structure Analysis: Conventional Criteria versus New Alternatives. Structural Equation Modeling: A Multidisciplinary Journal, 6, 1-55. https://doi.org/10.1080/10705519909540118

Huang, Y., \& Zhao, N. (2020). Generalized Anxiety Disorder, Depressive Symptoms and Sleep Quality during COVID-19 Outbreak in China: A Web-Based Cross-Sectional Survey. Psychiatry Research, 288, Article ID: 112954. https://doi.org/10.1016/j.psychres.2020.112954

IBM Corp (2013). IBM SPSS Statistics for Windows, Version 22.0. IBM Corp.

Larsen, E. M., Donaldson, K. R., Liew, M., \& Mohanty, A. (2021). Conspiratorial Thinking during COVID-19: The Roles of Paranoia, Delusion-Proneness, and Intolerance of Uncertainty. Frontiers in Psychiatry, 12, Article ID: 698147. https://doi.org/10.3389/fpsyt.2021.698147

Lee, S. A. (2020). Coronavirus Anxiety Scale: A Brief Mental Health Screener for COVID-19 Related Anxiety. Death Studies, 44, 393-401. https://doi.org/10.1080/07481187.2020.1748481

Li, Y., Zhang, H., Feng, Z., Chen, S., Liu, T., Chen, X., Tang, J., \& Liao, Y. (2016). Life Events, Anxiety and Depression among Doctors and Nurses in the Emergency Department: A Study from Eleven General Hospital in Hunan Province, China. Journal of Psychiatry and Brain Science, 1, 1-7. https://doi.org/10.20900/jpbs.20160002

Liu, S., Yang, L., Zhang, C., Xiang, Y., Liu, Z., Hu, S., \& Zhang, B. (2020). Online Mental Health Services in China during the COVID-19 Outbreak. The Lancet Psychiatry, 7, e17-e18. https://doi.org/10.1016/S2215-0366(20)30077-8 
Luceño-Moreno, L., Talavera-Velasco, B., García-Albuerne, Y., \& Martín-García, J. (2020). Symptoms of Posttraumatic Stress, Anxiety, Depression, Levels of Resilience and Burnout in Spanish Health Personnel during the COVID-19 Pandemic. International Journal of Environmental Research and Public Health, 17, Article ID: 5514. https://doi.org/10.3390/ijerph17155514

Muthén, L. K., \& Muthén, B. O. (2011). Mplus User’s Guide (Version 7). Muthén \& Muthén.

Padrós-Blázquez, F., López-Solà, C., Cruz-García, M. A., \& Martínez-Medina, M. P. (2019). PAMTA Worry Model (Perception of Future Threat, Activation, Motivation, Thought \& Action): Functional and Pathological Worry. Revista Argentina de Clínica Psicológica, 28, 190-198.

Padrós-Blázquez, F., Montoya-Pérez, K. S., Bravo-Calderón, M. A., \& Martínez-Medina, M. P. (2020). Propiedades psicométricas del Inventario de Ansiedad de Beck (BAI, Beck Anxiety Inventory) en población general de México [Psychometric Properties of the Beck Anxiety Inventory (BAI) in the General Population of Mexico]. Ansiedad $y$ Estrés, 26, 181-187. https://doi.org/10.1016/j.anyes.2020.08.002

Preti, E., Di Mattei, V., Perego, G., Ferrari, F., Mazzetti, M., Taranto, P. et al. (2020). The Psychological Impact of Epidemic and Pandemic Outbreaks on Healthcare Workers: Rapid Review of the Evidence. Current Psychiatry Reports, 22, Article No. 43. https://doi.org/10.1007/s11920-020-01166-Z

Priego-Parra, B. A., Triana-Romero, A., Pinto-Galvez, S. M., Duran-Ramos, C., Salas-Nolasco, O., Manriquez-Reyes, M., Ramos-de-la-Medina, A., \& Remes-Troche, J. M. (2020). Anxiety, Depression, Attitudes, and Internet Addiction during the Initial Phase of the 2019 Coronavirus Disease (COVID-19) Epidemic: A Cross-Sectional Study in México. MedRxiv. https://doi.org/10.1101/2020.05.10.20095844

Robles, R., Varela, R., Jurado, S., \& Páez, F. (2001). Versión mexicana del Inventario de Ansiedad de Beck: Propiedades psicométricas [Mexican Version of the Beck Anxiety Inventory: Psychometric Properties]. Revista Mexicana de Psicología, 18, 211-218.

Roy, D., Tripathy, S., Kar, S. K., Sharma, N., Verma, S. K., \& Kaushal, V. (2020). Study of Knowledge, Attitude, Anxiety \& Perceived Mental Healthcare Need in Indian Population during COVID-19 Pandemic. Asian Journal of Psychiatry, 51, Article ID: 102083. https://doi.org/10.1016/j.ajp.2020.102083

Sanz, J., \& Navarro, M. E. (2003). Propiedades psicométricas de una versión española del inventario de ansiedad de beck (BAI) en estudiantes universitarios [The Psychometric Properties of a Spanish Version of the Beck Anxiety Inventory (BAI) in a University Students Sample]. Ansiedad y Estrés, 9, 59-84.

Swami, V., \& Barron, D. (2020). Analytic Thinking, Rejection of Coronavirus (COVID-19) Conspiracy Theories, and Compliance with Mandated Social-Distancing: Direct and Indirect Relationships in a Nationally Representative Sample of Adults in the United Kingdom. OSF.

World Health Organization (WHO) (2020). WHO Director-General's Opening Remarks at the Mediabriefing on COVID-19.

https://www.who.int/director-general/speeches/detail/who-director-general-s-openingremarks-at-the-media-briefing-on-covid-19---11-march-2020 